\title{
BMJ Open Risk factors for persistent and new chronic opioid use in patients undergoing total hip arthroplasty: a retrospective cohort study
}

\author{
Maria C S Inacio, ${ }^{1}$ Craig Hansen, ${ }^{2}$ Nicole L Pratt, ${ }^{1}$ Stephen E Graves, ${ }^{3}$ \\ Elizabeth E Roughead ${ }^{1}$
}

To cite: Inacio MCS, Hansen C, Pratt NL, et al. Risk factors for persistent and new chronic opioid use in patients undergoing total hip arthroplasty:

a retrospective cohort study. BMJ Open 2016;6:e010664. doi:10.1136/bmjopen-2015010664

- Prepublication history for this paper is available online. To view these files please visit the journal online (http://dx.doi.org/10.1136/ bmjopen-2015-010664).

Received 25 November 2015 Revised 17 March 2016 Accepted 23 March 2016

CrossMark

For numbered affiliations see end of article.

Correspondence to Dr Maria CS Inacio; maria. inacio@unisa.edu.au

\author{
ABSTRACT \\ Objectives: To determine chronic opioid use pre-THA \\ (total hip arthroplasty) and post-THA, and risk factors \\ for persistent or new chronic opioid use post-THA. \\ Design: Retrospective cohort study. \\ Setting: Australian Government Department of \\ Veterans' Affairs health claims database.
}

Participants: 9525 patients who had an elective unilateral THA between 1/01/2001 and 12/31/2012 .

Primary outcome measure: Chronic opioid use. Defined as 90 days of continuous opioid use or 120 days of non-continuous use.

Results: Pre-THA, $6.2 \%(n=593)$ of patients were chronic users, while $5.2 \%(n=492)$ were post-THA. Among the 492 postoperative chronic users, 302 $(61 \%)$ were chronic users pre-THA and post-THA and $190(39 \%)$ became new chronic users after surgery. Risk factors for persistent chronic use were younger age (OR=0.96, $95 \% \mathrm{Cl} 0.93$ to 0.99/1-year increment), back pain (OR=1.99, $95 \% \mathrm{Cl} 1.20$ to 3.23 ), diabetes (OR=3.52, $95 \% \mathrm{Cl} 1.05$ to 11.8 ), hypnotics use (OR=2.52, 95\% $\mathrm{Cl} 1.48$ to 4.30 ) and higher pre-THA opioid exposure (compared with opioid use for 94157 days, $157-224$ days ( $O R=3.75,95 \% \mathrm{Cl} 2.28$ to $6.18), 225+$ days ( $O R=5.18,95 \% \mathrm{Cl} 2.92$ to 9.19 ). Risk factors for new chronic opioid use post-THA were being a woman ( $\mathrm{OR}=1.40,95 \% \mathrm{Cl} 1.00$ to 1.96$)$, back pain (OR=3.90, 95\% $\mathrm{Cl} 2.85$ to 5.33), depression $(\mathrm{OR}=1.70,95 \% \mathrm{Cl} 1.20$ to 2.41 ), gastric acid disease $(\mathrm{OR}=1.62,95 \% \mathrm{Cl} 1.16$ to 2.25$)$, migraine $(\mathrm{OR}=5.11$, $95 \% \mathrm{Cl} 1.08$ to 24.18 ), liver disease (OR=4.33, $95 \% \mathrm{Cl}$ 1.08 to 17.35 ), weight loss ( $O R=2.60,95 \% \mathrm{Cl} 1.06$ to 6.39), dementia ( $\mathrm{OR}=2.19,95 \% \mathrm{Cl} 1.04$ to 4.61 ), hyperlipidaemia ( $\mathrm{OR}=1.38,95 \% \mathrm{Cl} 1.00$ to 1.91$)$, hypnotics (OR=1.56, $95 \% \mathrm{Cl} 1.13$ to 2.16$)$ and antineuropathic pain medication use $(\mathrm{OR}=3.11,95 \% \mathrm{Cl}$ 2.05 to 4.72 ).

Conclusions: Patients undergoing THA are exposed to opioids for long periods of time, putting them at high risk of harm related to opioid use. We identified groups at risk of chronic opioid use, including younger patients and women, as well as modifiable risk factors of chronic opioid use, including level of opioid

\section{Strengths and limitations of this study}

- In a cohort of 9525 patients undergoing total hip arthroplasties (THAs), we found that $5 \%$ of the patients were chronic opioid users after their surgery. Of these, $61 \%$ were persistent chronic users (ie, had been chronic opioid users prior to surgery and continued after surgery), and 39\% became chronic users after surgery.

- This study also identified indicators of chronic opioid use that can be used by clinicians for risk stratification prior to surgery, and to target patient groups for suitable pain management interventions presurgery and postsurgery. Specifically, back pain, diabetes and preoperative use of hypnotics were strong risk factors for the persistent and new development of chronic opioid use. Additional risk factors for persistent use included younger age and greater use of opioids prior to surgery, while for new chronic use these included being a woman, depression, migraine, gastric acid disease and antineuropathic pain medications.

- The limitations of this study include a conservative definition of chronic opioid as someone who was prescribed opioids for 90 consecutive days or 120 non-consecutive days, and inability to determine the specific reasons why analgesic medications were prescribed to patients.

- The strengths of this study include a large and fully captured patient cohort (ie, no missing data and attrition only related to death), a comprehensive assessment of patient comorbidities using three comorbidity measures, and the use of pharmacy data to determine opioid use instead of patient-reported use which can suffer from response bias.

exposure presurgery and hypnotic use. These indicators of chronic opioid use can be used by clinicians to target patient groups for suitable pain management interventions. 


\section{BACKGROUND}

Total hip arthroplasty (THA) is the recommended treatment for patients with hip osteoarthritis that have failed both pharmacological and non-pharmacological treatment for the severe pain, and limited function caused by their condition. ${ }^{1}$ THA is the fourth most common surgical procedure in the USA, with 468000 performed in $2012^{2}$; it is one of the top 20 most common surgical procedures in Australia, with 26000 performed in 2013. ${ }^{3}$ THA is considered a clinically effective, successful operation with reported cost-effectiveness. ${ }^{1}$ However, while joint-related pain is expected to be resolved after surgical rehabilitation, there is a high prevalence of patients who report persistent chronic pain and some patients who report chronic pain development subsequent to the procedure. $^{4}$

Chronic and persistent pain post-THA occurs in $7-23 \%$ of patients. ${ }^{4} 5$ One study reported moderateto-severe hip pain after primary THA in $8 \%$ of patients. ${ }^{6}$ Other studies suggested that $3-25 \%$ of patients take opioid medications for almost 5 years after their surgery. ${ }^{6}{ }^{7}$ There are several reasons that suggest the use of opioids in patients with THA is high, and abuse of these medications could affect these patients. First, it is well established that the use of opioids has increased worldwide for all non-cancer chronic pain management. ${ }^{8-11}$ In the treatment of musculoskeletal pain, opioids use increased by $50 \%$ between 2006 and $2010,{ }^{12}$ and surgeons are reportedly some of the highest prescribers of these medications. ${ }^{13}$ Second, as opioids are recommended for the treatment of osteoarthritis ${ }^{1}$ and surgical recovery, ${ }^{14}$ patients undergoing THA are likely to be exposed to opioids for long periods of time, increasing their chance of developing tolerance, hyperalgesia, ${ }^{15}$ and other dangerous and potentially costly opioid-related side effects. ${ }^{16}$ Third, the comorbidity burden of patients undergoing THA has increased in the past two decades, ${ }^{17-19}$ suggesting that patients can, and are likely to, be suffering from other types of pain and taking opioids for these other conditions, which also affect their surgical outcomes. ${ }^{20}$ Finally, in addition to the high exposure to these medications, there is the potential of adverse events associated with opioid use in surgical recovery. ${ }^{14}$ The higher medical complexity of the patients undergoing THA creates potential interactions between these opioid medications and the specific surgical outcomes of the procedure. Currently it is not well understood how opioids are used in this patient population and who is at risk of harm.

Understanding who is at risk of persistent chronic opioid use and developing new chronic use in this patient population can be useful to the surgeons, the patients themselves and the general healthcare system of which they are a part. Our study was conducted to identify patients at a high risk of chronic opioid use who may benefit from targeted interventions for better pain management strategies and opioid use education. Specifically, the purpose of this study was to (1) determine the prevalence of chronic opioid use before and after THA surgery, and (2) determine the characteristics associated with persistent chronic opioid use or becoming a new chronic user after surgery.

\section{METHODS}

\section{Study design, setting and study sample}

A retrospective cohort study was conducted. Patients who underwent a THA procedure between 1/01/2001 and 12/31/2012 were included in the study. The study cohort comprised of patients who received care subsidised by the Australian Government Department of Veterans' Affairs (DVA). The DVA administrative claims database, which includes detailed information on all inpatient hospitalisations, prescription medications, medical procedures and allied health services provided to veterans, was used for the study. The DVA's client file, which contains information on gender, date of birth, date of death and family status for a treatment population of 242000 veterans and spouses in September 2011, was also used. In the prescription data set, medications are coded according to the WHO anatomic, therapeutic and chemical classification (ATC), ${ }^{21}$ and the Australian Pharmaceutical Benefits Schedule (PBS) item codes. ${ }^{22}$ In the inpatient hospitalisation data set, encounters are coded using the International Classification of Diseases, 10th Revision, Australian Modification (ICD-10-AM) codes. $^{23}$

Patients older than 18 years of age were selected for the study if they underwent elective unilateral THA (identified using ICD-10-AM procedure code 4931 800), did not have other hip or knee arthroplasties within 1 year of the index THA, and did not have history of cancer (ICD-10-AM C00.x-C26.x, C30.x-C34.x, C37.xC41.x, C43.x, C45.x-C58.x, C60.x-C76.x, C81.x-C85.x, C88.x,C90.x-C97.x, C77.x-C80.x，C81.x-C85.x，C88.x, C96.x, C90.0, C90.2 and antineoplastic and immunomodulating agents medication history ATC codes L01*). The cohort was initially comprised of 10018 THAs belonging to 9373 patients. Of these, 493 THAs were not included in the final sample as they either experienced a revision $(\mathrm{N}=202)$ or died $(\mathrm{N}=290)$ within a year of surgery or did not have complete 1-year follow-up $(\mathrm{N}=1)$. Patients with revisions or who died within 1 year were excluded to reduce the effect these events could have on the amount of opioids a patient would take; thus, an accurate description of chronic opioid use could be determined. The final cohort comprised 9525 THAs given to 8925 patients (8325 patients had one THA and 600 had two surgeries more than 1 year apart).

\section{Outcomes of interest}

Chronic opioid use after surgery was the main outcome of interest. Chronic opioid use was defined as having any number of opioid prescriptions or dosing for at least 90 days continuously, or opioid prescriptions for 120 
non-consecutive days. ${ }^{24}$ The number of days was obtained from the number of units supplied. No gap days between one prescription supply and another were allowed when determining consecutive prescription of opioids. New chronic users were those who did not have chronic use prior to their THA. Persistent chronic opioid users were those with chronic opioid use before and after surgery.

Opioids (ATC code $=\mathrm{N} 02 \mathrm{~A}^{*}$, inclusive of opioid-like medications such as Tramadol) 365 days pre-THA (admission date) and post-THA (discharge date) were extracted from the DVA prescription database, and the number of dispensed prescriptions and the days of expected utilisation were calculated. Dosages were converted to oral morphine equivalents (OMEs), ${ }^{25}$ and the daily OMEs were summed across the days within the pre-THA and post-THA periods to estimate the total OME for these time periods. When determining whether patients were chronic opioid users post-THA, the immediate 90-day period after THA was excluded as the use of opioids in this period is related to surgical recovery and rehabilitation. Therefore, each patient had 275 potential days of medication utilisation post-THA. To obtain a similar exposure period preoperatively, we excluded the 90-day period between 365 and 275 days prior surgery. Patients were assigned to the opioid use categories of 'chronic', 'some' and 'none' opioid use for the periods of pre-THA and post-THA. After classifying chronic users, the remaining opioid users were classified as 'some' opioid use if they did not fit the chronic criteria, and those without any opioid dispensing were assigned to the 'none' category.

\section{Risk factors}

Age, sex, surgical indication, bilaterality, opioid-related comorbidities, other medical comorbidities and other analgesic medication were evaluated as risk factors of persistent or new chronic opioid use after surgery. Comorbidities were identified using a combination of the RxRisk-V, Elixhauser and Charlson measures. ${ }^{26} 27$ Using these three comorbidity measures provided a comprehensive ascertainment of conditions because it used both medication dispensing history and hospital encounters of the patients in the year prior to their surgery. The opioid-related comorbidities investigated included depression, back pain, anxiety, psychoses, alcohol abuse, bipolar disorder and drug abuse. The 49 medical comorbidities investigated, which included cardiovascular and blood, endocrine, gastrointestinal, musculoskeletal, neurological, nutritional, renal, respiratory, and other body systems, can be seen in table 1 . Additional analgesic medication evaluated included nonsteroids anti-inflammatories (ATC code $=\mathrm{M} 01 \mathrm{~A}^{*}$ ), muscle relaxants (ATC code $=\mathrm{M} 03 *$ ), antineuropathic pain medications (ATC codes=N06AA09, N06AX21, N03AX12, N03AX16), ${ }^{28}$ hypnotics (ATC code $=\mathrm{N} 05 \mathrm{C} *$, inclusive of sedatives) and corticosteroids (ATC codes=H02AA*, $\left.\mathrm{H} 2 \mathrm{AB}^{*}\right)$. Since the comorbidities of pain treated with opioids, pain treated with anti-inflammatory medications and steroid-responsive disorders were identified using only the RxRisk-V medication comorbidity measure we did not include them in our final analyses, as these are likely to be highly correlated to the other analgesic medication evaluated. Days of opioid use (per quartile of days) and average daily use were investigated as risk factors for persistent chronic opioid use.

\section{Statistical analyses}

Frequencies, proportions, medians, IQR, means and SD described the study sample. The prevalence of opioid use, as well as crude overall mean OME taken and days of opioid use per subgroup were calculated. The adjusted change in mean OME and mean days of opioid use from pre-THA to post-THA were calculated using generalised linear models. Logistic regression models were used to identify risk factors associated with persistent chronic opioid use and new chronic opioid use after surgery. In both models, all candidate covariates were modelled in a bivariate model with the outcome of interest. If their association with the outcome had a $\mathrm{p}<0.2$, then these were included in the subsequent multivariable model. Collinearity between the variables in final models was evaluated, and tolerance values were $>0.1$ in all cases. ORs and 95\% CIs are provided. All tests were two-sided, and $\alpha=0.05$ was considered statistically significant. SAS V.9.4 (SAS Institute, Cary, North Carolina, USA) was used for all analyses.

\section{Sensitivity analysis}

High and long-term use of non-steroidal anti-inflammatory drugs are risk factors for gastric acid disease, a condition treated with proton-pump inhibitors; ${ }^{29}{ }^{30}$ therefore, we tested this interaction in a sensitivity analysis-no interaction was found and data are not shown.

\section{Patient involvement}

No patients were involved in the design of this study, in developing the outcome measures nor in the conduct of the study. There are no plans to disseminate the results to study participants.

\section{RESULTS}

Our cohort of 9525 primary THAs was $51.3 \% \quad(n=4891)$ women and had a median age of 80 years (5th-95th centile 76-84 years) at the time of surgery. Table 1 describes patients' characteristics, comorbidities and other analgesic medication use pre-THA and post-THA as per their pre-THA chronic opioid use status.

Presurgery, $6.2 \% \quad(n=593)$ of patients were considered chronic opioid users, while $5.2 \% \quad(\mathrm{n}=492)$ were users postsurgery. Of the 492 chronic users post-THA, $61.4 \%$ $(\mathrm{n}=302)$ were persistent chronic users (chronic users pre-THA and post-THA) and $38.6 \%(\mathrm{n}=190)$ became chronic users after surgery (ie, 38 were considered 'none' and 152 were considered 'some' users pre-THA). 
Table 1 Descriptive characteristics of the total hip arthroplasty study cohort

\begin{tabular}{|c|c|c|c|c|}
\hline Characteristic & All & None & Some & Chronic \\
\hline Total, n (\%) & 9525 & $5138(53.9)$ & 3794 (39.8) & $593(6.2)$ \\
\hline Age at surgery, median (5th-95th centile), years & $80(76-84)$ & $81(63-88)$ & $80(61-89)$ & $81(59-89)$ \\
\hline \multicolumn{5}{|l|}{ Sex, $n(\%)$} \\
\hline Women & $4891(51.3)$ & $2558(49.8)$ & $1977(52.1)$ & $356(60.0)$ \\
\hline Men & 4634 (48.7) & $2580(50.2)$ & 1817 (47.9) & $237(40.0)$ \\
\hline Bilateral (more than 365 days), $n$ (\%) & $1200(12.6)$ & 669 (13.0) & $473(12.5)$ & $58(9.8)$ \\
\hline \multicolumn{5}{|l|}{ Year of operation, $n(\%)$} \\
\hline $2001-2002$ & $1738(18.2)$ & $1001(19.5)$ & $694(18.3)$ & $43(7.3)$ \\
\hline 2003-2004 & 1840 (19.3) & $980(19.1)$ & $786(20.7)$ & $74(12.5)$ \\
\hline $2005-2006$ & $1654(17.4)$ & $925(18.0)$ & $651(17.2)$ & $78(13.2)$ \\
\hline 2007-2008 & $1590(16.7)$ & $853(16.6)$ & $612(16.1)$ & $125(21.1)$ \\
\hline 2009-2010 & 1454 (15.3) & $750(14.6)$ & $572(15.1)$ & $132(22.3)$ \\
\hline 2011-2012 & $1249(13.1)$ & $629(12.2)$ & 479 (12.6) & $141(23.8)$ \\
\hline \multicolumn{5}{|l|}{ Surgical indication, $\mathrm{n}(\%)$} \\
\hline ICD-10-AM M161: other primary osteoarthritis & $7826(82.2)$ & $4241(82.5)$ & $3092(81.5)$ & $493(83.1)$ \\
\hline ICD-10-AM M169: osteoarthritis unspecified & $882(9.3)$ & $513(10.0)$ & $342(9.0)$ & $27(4.6)$ \\
\hline Other & $817(8.6)$ & $384(7.5)$ & $360(9.5)$ & $73(12.3)$ \\
\hline \multicolumn{5}{|l|}{ Opioid-related comorbidities } \\
\hline Depression, n (\%) & 1695 (17.8) & $755(14.7)$ & $764(20.1)$ & $176(29.7)$ \\
\hline Back pain, $n(\%)$ & $1367(14.4)$ & $466(9.1)$ & 694 (18.3) & 207 (34.9) \\
\hline Anxiety, n (\%) & 1167 (12.3) & $445(8.7)$ & $569(15.0)$ & $153(25.8)$ \\
\hline Psychoses, n (\%) & $191(2.0)$ & $96(1.9)$ & $74(2.0)$ & $21(3.5)$ \\
\hline Alcohol abuse, $n(\%)$ & $88(0.9)$ & $36(0.7)$ & 45 (1.2) & 7 (1.2) \\
\hline Bipolar disorder, n (\%) & $26(0.3)$ & $14(0.3)$ & $11(0.3)$ & $1(0.2)$ \\
\hline Drug abuse, n (\%) & $11(0.1)$ & $4(0.1)$ & $3(0.1)$ & $4(0.7)$ \\
\hline \multicolumn{5}{|l|}{ Cardiovascular/blood comorbidities } \\
\hline Hypertension, n (\%) & $5384(56.5)$ & $2789(54.3)$ & $2215(58.4)$ & $380(64.1)$ \\
\hline Anticoagulation agents/coagulopathy, n (\%) & $5071(53.2)$ & $2676(52.1)$ & $2077(54.7)$ & $318(53.6)$ \\
\hline Hyperlipidaemia, n (\%) & $3621(38.0)$ & $1819(35.4)$ & $1534(40.4)$ & $268(45.2)$ \\
\hline IHD hypertension, n (\%) & $3341(35.1)$ & $1722(33.5)$ & $1392(36.7)$ & $227(38.3)$ \\
\hline Antiplatelet agents, n (\%) & $3213(33.7)$ & $1594(31.0)$ & 1377 (36.3) & $242(40.8)$ \\
\hline Arrhythmias, n (\%) & 1837 (19.3) & 937 (18.2) & $774(20.4)$ & $126(21.2)$ \\
\hline Congestive heart failure, $\mathrm{n}(\%)$ & $1277(13.4)$ & $556(10.8)$ & $585(15.4)$ & $136(22.9)$ \\
\hline Angina, $\mathrm{n}(\%)$ & $1112(11.7)$ & $484(9.4)$ & $530(14.0)$ & $98(16.5)$ \\
\hline Myocardial infarction, n (\%) & $241(2.5)$ & $112(2.2)$ & $112(3.0)$ & $17(2.9)$ \\
\hline Peripheral vascular disease, $\mathrm{n}(\%)$ & $225(2.4)$ & $105(2.0)$ & $100(2.6)$ & $20(3.4)$ \\
\hline Valvular disease, $\mathrm{n}(\%)$ & $225(2.4)$ & $118(2.3)$ & $96(2.5)$ & $11(1.9)$ \\
\hline Cerebrovascular disorders, n (\%) & $201(2.1)$ & $90(1.8)$ & $95(2.5)$ & $16(2.7)$ \\
\hline Pulmonary circulation disorders, $\mathrm{n}(\%)$ & $109(1.1)$ & $54(1.1)$ & $42(1.1)$ & $13(2.2)$ \\
\hline \multicolumn{5}{|l|}{ Endocrine comorbidities } \\
\hline Diabetes uncomplicated, n (\%) & 1007 (10.6) & $474(9.2)$ & $440(11.6)$ & $93(15.7)$ \\
\hline Hypothyroidism, n (\%) & $674(7.1)$ & $348(6.8)$ & $260(6.9)$ & $66(11.1)$ \\
\hline Diabetes with complications, $\mathrm{n}(\%)$ & $624(6.6)$ & $284(5.5)$ & $281(7.4)$ & $59(9.9)$ \\
\hline Pancreatic insufficiency, n (\%) & $15(0.2)$ & $4(0.1)$ & $10(0.3)$ & $1(0.2)$ \\
\hline \multicolumn{5}{|l|}{ Gastrointestinal comorbidities } \\
\hline Gastric acid disorder, n (\%) & $4267(44.8)$ & $1981(38.6)$ & $1904(50.2)$ & $382(64.4)$ \\
\hline Liver disease (severe) or failure, $\mathrm{n}(\%)$ & $361(3.8)$ & $121(2.4)$ & $173(4.6)$ & $67(11.3)$ \\
\hline Peptic ulcer disease, n (\%) & $95(1.0)$ & $47(0.9)$ & $40(1.1)$ & $8(1.3)$ \\
\hline Inflammatory bowel syndrome, n (\%) & $80(0.8)$ & $40(0.8)$ & $37(1.0)$ & $3(0.5)$ \\
\hline Liver disease (mild), n (\%) & $25(0.3)$ & $9(0.2)$ & $13(0.3)$ & $3(0.5)$ \\
\hline Hepatitis C, n (\%) & $0(0.0)$ & $0(0.0)$ & $0(0.0)$ & $0(0.0)$ \\
\hline \multicolumn{5}{|l|}{ Musculoskeletal/pain-related comorbidities } \\
\hline Osteoporosis/Paget's, n (\%) & $1189(12.5)$ & $564(11.0)$ & $496(13.1)$ & $129(21.8)$ \\
\hline Gout, n (\%) & $950(10.0)$ & $471(9.2)$ & 407 (10.7) & $72(12.1)$ \\
\hline RA/collage vascular disorders, $n(\%)$ & $108(1.1)$ & $32(0.6)$ & $62(1.6)$ & $14(2.4)$ \\
\hline Migraine, $\mathrm{n}(\%)$ & $28(0.3)$ & $9(0.2)$ & $11(0.3)$ & 8 (1.3) \\
\hline
\end{tabular}


Table 1 Continued

\begin{tabular}{|c|c|c|c|c|}
\hline Characteristic & All & None & Some & Chronic \\
\hline \multicolumn{5}{|l|}{ Neurological comorbidities } \\
\hline Dementia, n (\%) & $191(2.0)$ & $97(1.9)$ & $65(1.7)$ & $29(4.9)$ \\
\hline Epilepsy & $421(4.4)$ & $143(2.8)$ & $210(5.5)$ & $68(11.5)$ \\
\hline Parkinson's disease, $\mathrm{n}(\%)$ & $152(1.6)$ & $62(1.2)$ & $70(1.8)$ & $20(3.4)$ \\
\hline Other neurological disorders, n (\%) & 119 (1.2) & $60(1.2)$ & $47(1.2)$ & $12(2.0)$ \\
\hline Paralysis (or paraplegia/hemiplegia), n (\%) & $63(0.7)$ & $26(0.5)$ & $32(0.8)$ & $5(0.8)$ \\
\hline \multicolumn{5}{|l|}{ Nutritional/obesity comorbidities } \\
\hline Deficiency anaemia, n (\%) & $152(1.6)$ & $65(1.3)$ & $72(1.9)$ & $15(2.5)$ \\
\hline Obesity, n (\%) & $146(1.5)$ & $57(1.1)$ & $77(2.0)$ & $12(2.0)$ \\
\hline Weight loss, n (\%) & $87(0.9)$ & $31(0.6)$ & 49 (1.3) & $7(1.2)$ \\
\hline Blood loss anaemia, n (\%) & $60(0.6)$ & $24(0.5)$ & $29(0.8)$ & $7(1.2)$ \\
\hline Malnutrition, $n(\%)$ & $16(0.2)$ & $9(0.2)$ & $5(0.1)$ & $2(0.3)$ \\
\hline Hyperkalaemia, n (\%) & $3(0.0)$ & $3(0.1)$ & $0(0.0)$ & $0(0.0)$ \\
\hline \multicolumn{5}{|l|}{ Renal/urological } \\
\hline Renal disease/failure, $\mathrm{n}(\%)$ & $410(4.3)$ & $168(3.3)$ & $196(5.2)$ & $46(7.8)$ \\
\hline Benign prostatic hypertrophy, n (\%) & $352(3.7)$ & $189(3.7)$ & $137(3.6)$ & $26(4.4)$ \\
\hline \multicolumn{5}{|l|}{ Respiratory comorbidities } \\
\hline Reactive airway disease, n (\%) & $1978(20.8)$ & $931(18.1)$ & $888(23.4)$ & $159(26.8)$ \\
\hline Chronic pulmonary disease, $\mathrm{n}(\%)$ & $504(5.3)$ & $230(4.5)$ & $228(6.0)$ & $46(7.8)$ \\
\hline Tuberculosis, n (\%) & $0(0.0)$ & $0(0.0)$ & $0(0.0)$ & $0(0.0)$ \\
\hline \multicolumn{5}{|l|}{ Miscellaneous comorbidities } \\
\hline Allergies, n (\%) & $1327(13.9)$ & $592(11.5)$ & $618(16.3)$ & $117(19.7)$ \\
\hline Glaucoma, n (\%) & $897(9.4)$ & $494(9.6)$ & $356(9.4)$ & $47(7.9)$ \\
\hline Smoking, n (\%) & $90(0.9)$ & $32(0.6)$ & $53(1.4)$ & $5(0.8)$ \\
\hline Psoriasis, $\mathrm{n}(\%)$ & $46(0.5)$ & $19(0.4)$ & $24(0.6)$ & $3(0.5)$ \\
\hline Transplant, n (\%) & $2(0.0)$ & $1(0.0)$ & $1(0.0)$ & $0(0.0)$ \\
\hline HIV, n (\%) & $0(0.0)$ & $0(0.0)$ & $0(0.0)$ & $0(0.0)$ \\
\hline \multicolumn{5}{|l|}{ Other analgesic medication use } \\
\hline \multicolumn{5}{|l|}{ Pre-THA } \\
\hline NSAIDs, n (\%) & $6093(64.0)$ & 3007 (58.5) & $2722(71.7)$ & $364(61.4)$ \\
\hline Hypnotics and sedatives, $\mathrm{n}(\%)$ & $1904(20.0)$ & $693(13.5)$ & $1012(26.7)$ & $199(33.6)$ \\
\hline Corticosteroids, n (\%) & 1275 (13.4) & $474(9.2)$ & $672(17.7)$ & $129(21.8)$ \\
\hline Antineuropathic pain, $\mathrm{n}(\%)$ & $657(6.9)$ & $205(4.0)$ & $333(8.8)$ & $119(20.1)$ \\
\hline Muscle relaxants, $\mathrm{n}(\%)$ & $27(0.3)$ & $7(0.1)$ & $17(0.4)$ & $3(0.5)$ \\
\hline \multicolumn{5}{|l|}{ Post-THA } \\
\hline NSAIDs, n (\%) & $4288(45.0)$ & $2033(39.6)$ & 1969 (51.9) & $286(48.2)$ \\
\hline Hypnotics and sedatives, $n(\%)$ & $1950(20.5)$ & $762(14.8)$ & $982(25.9)$ & $206(34.7)$ \\
\hline Corticosteroids, n (\%) & $1242(13.0)$ & $497(9.7)$ & $623(16.4)$ & $122(20.6)$ \\
\hline Antineuropathic pain, n (\%) & $678(7.1)$ & $233(4.5)$ & $326(8.6)$ & $119(20.1)$ \\
\hline Muscle relaxants, $\mathrm{n}(\%)$ & $24(0.3)$ & $5(0.1)$ & $15(0.4)$ & $4(0.7)$ \\
\hline
\end{tabular}

Overall and by preoperative opioid utilisation status, 2001-2012.

ICD-10-AM, International Classification of Diseases, 10th Revision, Australian Modification; NSAID, non-steroidal anti-inflammatory drugs; RA, rheumatoid arthritis; THA, total hip arthroplasty.

On average, a chronic opioid user before surgery had 55.5 (95\% CI 51.4 to 59.7 ) OMEs $\mathrm{mg} /$ day and was dispensed opioids for 189.9 (95\% CI 185.69 to 193.9) days. Postsurgery they had 57.5 (95\% CI 52.1 to 62.8) OMEs $\mathrm{mg} /$ day and were dispensed opioids for 193.0 (95\% CI 188.8 to 197.1) days. See table 2 for prevalence of opioid use type, daily OMEs and average number of days for each group, as well as changes in the group pre-THA and post-THA.

Risk factors for persistent chronic opioid use were younger age $(\mathrm{OR}=0.96,95 \%$ CI 0.93 to $0.99 / 1$-year increment), presence of back pain ( $\mathrm{OR}=1.99,95 \%$ CI 1.20 to 3.23$)$, uncomplicated diabetes $(\mathrm{OR}=3.52,95 \%$
CI 1.05 to 11.8 ) and use of hypnotics pre-THA $(\mathrm{OR}=2.52,95 \%$ CI 1.48 to 4.30$)$. The number of days on opioids prior to surgery was associated with odds of continuing to be a chronic opioid user after surgery after 94 days using opioids. Compared with opioid use for 94-157 days, patients who used opioids for 157224 days had a $3.75(95 \%$ CI 2.28 to 6.18$)$ higher odds of being a persistent user, and those who used it for $225+$ days had a 5.18 (95\% CI 2.92 to 9.19) higher odds (table 3).

Risk factors for patients to develop chronic opioid use after THA were being a woman $(\mathrm{OR}=1.40,95 \%$ CI 1.00 to 1.96$)$, presence of back pain $(\mathrm{OR}=3.90,95 \%$ CI 
Table 2 Prevalence of opioid use, mean daily oral morphine equivalents use, and days of use pre-THA and post-THA by opioid user status, and change in daily use and days by pre-THA to post-THA status

\begin{tabular}{|c|c|c|c|c|}
\hline & \multirow{2}{*}{$\begin{array}{l}\text { Opioid use post-THA } \\
\text { Total }\end{array}$} & \multicolumn{3}{|l|}{ Opioid use pre-THA } \\
\hline & & None & Some & Chronic \\
\hline \multicolumn{5}{|c|}{ Prevalence, n (\%) } \\
\hline Total & 9525 & $5138(5339)$ & 3794 (39.8) & $593(6.2)$ \\
\hline None & $6626(69.6)$ & $4369(85.0)$ & $2146(56.6)$ & $111(18.7)$ \\
\hline Some & 2407 (25.3) & 731 (14.2) & $1496(39.4)$ & $180(30.4)$ \\
\hline Chronic & $492(5.2)$ & $38(0.7)$ & $152(4.0)$ & 302 (50.9) \\
\hline \multicolumn{5}{|c|}{ Daily OME use for group and change in daily OME use, ${ }^{*} \mathrm{mg}$, mean $(95 \% \mathrm{Cl})$} \\
\hline Total & & $0.0(0.0$ to 0.0$)$ & 38.3 (37.6 to 39.0$)$ & 55.5 (51.4 to 59.7$)$ \\
\hline None & $0.0(0.0$ to 0.0$)$ & $0.0(-0.1$ to 0.1$)$ & $-37.7(-38.4$ to -37.0$)$ & $-55.3(-59.4$ to -51.2$)$ \\
\hline Some & 37.5 (36.6 to 38.4$)$ & 36.6 (35.7 to 37.5$)$ & $-1.1(-2.1$ to -0.1$)$ & $-18.7(-22.9$ to -14.5$)$ \\
\hline Chronic & 57.5 (52.1 to 62.8$)$ & 56.2 (51.2 to 61.2$)$ & 18.6 (13.6 to 23.6$)$ & $0.9(-3.2$ to 5.0$)$ \\
\hline \multicolumn{5}{|c|}{ Days using opioids for group and change in days use, ${ }^{*}$ mean $(95 \% \mathrm{Cl})$} \\
\hline Total & & $0.0(0.0$ to 0.0$)$ & 27.0 (26.1 to 27.9$)$ & 189.9 (185.9 to 193.9$)$ \\
\hline None & $0.0(0.0$ to 0.0$)$ & $-0.2(-0.3$ to -0.1$)$ & $-25.9(-26.8$ to -25.0$)$ & $-187.0(-190.9$ to -183.1$)$ \\
\hline Some & 24.4 (23.3 to 25.5$)$ & 22.7 (21.6 to 23.8$)$ & $-3.0(-4.3$ to -1.7$)$ & $-164.0(-168.1$ to -159.9$)$ \\
\hline Chronic & 193.0 (188.8 to 197.1$)$ & 189.0 (184.8 to 193.2$)$ & 163.3 (159.1 to 167.5$)$ & $2.6(-2.3$ to 7.5$)$ \\
\hline
\end{tabular}

*Adjusted for age, sex, surgical indication, bilateral status, RxRisk-V comorbidity burden, back pain, year of operation, and prior THA and post-THA other analgesic medication use.

OME, oral morphine equivalents; THA, total hip arthroplasty.

2.85 to 5.33), depression ( $\mathrm{OR}=1.70$, 95\% CI 1.20 to 2.41), migraine ( $\mathrm{OR}=5.30,95 \%$ CI 1.12 to 25.01$)$, liver disease (mild; OR=4.33, 95\% CI 1.08 to 17.35), weight loss $(\mathrm{OR}=2.60,95 \%$ CI 1.06 to 6.39$)$, dementia $(\mathrm{OR}=2.19,95 \%$ CI 1.06 to 6.39$)$, gastric acid disease
(OR=1.62, 95\% CI 1.16 to 2.25), hyperlipidaemia $(\mathrm{OR}=1.38,95 \%$ CI 1.00 to 1.91$)$, and preoperative use of hypnotics (OR=1.56, 95\% CI 1.13 to 2.16$)$ and antineuropathic pain medication ( $\mathrm{OR}=3.11,95 \%$ CI 2.05 to 4.72; table 4).

Table 3 Risk factors of persistent chronic opioid use after THA in patients who were chronic user presurgery ( $N=302 / 593)$

\begin{tabular}{|c|c|c|c|c|}
\hline Risk factor & Crude OR $(95 \% \mathrm{Cl})$ & p Value & Adjusted OR $(95 \% \mathrm{Cl})$ & $\bar{p}$ Value \\
\hline \multicolumn{5}{|l|}{ Demographics } \\
\hline Age (per 10-year increment) & 0.97 (0.95 to 0.98$)$ & $<0.001$ & $0.96(0.93$ to 0.99$)$ & $<0.001^{*}$ \\
\hline \multicolumn{5}{|l|}{ Opioid-related comorbidities } \\
\hline Back pain & $1.69(1.20$ to 2.38$)$ & 0.003 & $1.99(1.20$ to 3.23$)$ & $0.008^{*}$ \\
\hline Depression & 1.60 (1.12 to 2.28$)$ & 0.009 & 1.14 (0.67 to 1.96$)$ & 0.629 \\
\hline Psychoses & $1.97(0.78$ to 4.96$)$ & 0.149 & 1.47 (0.39 to 5.42$)$ & 0.563 \\
\hline \multicolumn{5}{|l|}{ Medical comorbidities } \\
\hline Diabetes with complications & 2.19 (1.12 to 3.87$)$ & 0.007 & $3.52(1.05$ to 11.8$)$ & $0.042^{*}$ \\
\hline IHD hypertension & 0.80 (0.58 to 1.12$)$ & 0.199 & $0.66(0.41$ to 1.07$)$ & 0.090 \\
\hline Diabetes uncomplicated & $2.17(1.36$ to 3.45$)$ & 0.001 & 1.89 (0.78 to 4.57$)$ & 0.160 \\
\hline Liver disease (severe) or failure & 1.49 (0.89 to 2.50$)$ & 0.129 & 1.25 (0.59 to 2.66$)$ & 0.566 \\
\hline Migraine & $2.93(0.59$ to 14.6$)$ & 0.190 & $1.76(0.18$ to 17.3$)$ & 0.628 \\
\hline Hypertension & $1.28(0.92$ to 1.79$)$ & 0.147 & 0.98 (0.59 to 1.63$)$ & 0.934 \\
\hline RA/collage vascular disorders & $2.46(0.76$ to 7.92$)$ & 0.133 & 1.01 (0.25 to 4.71$)$ & 0.925 \\
\hline \multicolumn{5}{|l|}{ Analgesic use } \\
\hline Days using opioids prior to surgery & & $<0.001$ & & $<0.001$ \\
\hline$<94$ & $-\dagger$ & & $-\dagger$ & \\
\hline $94-156$ & Ref & & Ref & \\
\hline $157-224$ & 3.75 (2.28 to 6.18$)$ & & 3.63 (2.08 to 6.34$)$ & \\
\hline $225+$ & 4.85 (2.89 to 8.15$)$ & & $5.18(2.92$ to 9.19$)$ & \\
\hline Average daily use of opioids (per $10 \mathrm{OME}$ increment) & $1.11(1.06$ to 1.15$)$ & & $1.06(1.00$ to 1.11$)$ & 0.065 \\
\hline Pre-THA: hypnotics and sedatives & $1.72(1.21$ to 2.42$)$ & 0.002 & $2.52(1.48$ to 4.30$)$ & $<0.001^{*}$ \\
\hline
\end{tabular}

*Significant variables $(p<0.05)$ in final model.

†No cases of persistent chronic users in this group, could not model this level.

IHD, ischaemic heart disease; OME, oral morphine equivalents; RA, rheumatoid arthritis; Ref, reference; THA, total hip arthroplasty. 
Table 4 Risk factors for developing new chronic opioid use after THA surgery ( $N=190 / 8932$ )

\begin{tabular}{|c|c|c|c|c|}
\hline Risk factor & Crude OR (95\% CI) & p Value & Adjusted OR (95\% Cl) & p Value \\
\hline \multicolumn{5}{|l|}{ Demographics } \\
\hline Sex: women vs men & 1.47 (1.09 to 1.97$)$ & 0.011 & $1.40(1.00$ to 1.96$)$ & $0.049^{*}$ \\
\hline \multicolumn{5}{|l|}{ Opioid-related comorbidities } \\
\hline Back pain & $5.52(4.12$ to 7.41$)$ & $<0.001$ & 3.90 (2.85 to 5.33$)$ & $<0.001^{*}$ \\
\hline Depression & 2.13 (1.56 to 2.93$)$ & $<0.001$ & $1.70(1.20$ to 2.41$)$ & $0.003^{*}$ \\
\hline Alcohol abuse & 3.08 (1.23 to 7.71$)$ & 0.016 & $2.16(0.75$ to 6.22$)$ & 0.152 \\
\hline Psychoses & $2.98(1.55$ to 5.74$)$ & 0.001 & $1.39(0.65$ to 2.96$)$ & 0.392 \\
\hline Anxiety & 1.66 (1.14 to 2.43$)$ & 0.009 & $1.00(0.66$ to 1.50$)$ & 0.990 \\
\hline \multicolumn{5}{|l|}{ Medical comorbidities } \\
\hline Migraine & $5.16(1.19$ to 22.38$)$ & 0.028 & $5.11(1.08$ to 24.18$)$ & $0.040^{*}$ \\
\hline Liver mild disease & 7.37 (2.16 to 25.10$)$ & 0.001 & 4.33 (1.08 to 17.35$)$ & $0.039^{*}$ \\
\hline Weight loss & $3.82(1.64$ to 8.89$)$ & 0.002 & 2.60 (1.06 to 6.39$)$ & $0.038^{*}$ \\
\hline Dementia & 2.79 (1.40 to 5.56$)$ & 0.003 & 2.19 (1.04 to 4.61$)$ & $0.039^{*}$ \\
\hline Gastric acid disease & 2.49 (1.84 to 3.36$)$ & $<0.001$ & 1.62 (1.16 to 2.25$)$ & $0.004^{*}$ \\
\hline Hyperlipidaemia & 1.76 (1.32 to 2.34$)$ & $<0.001$ & $1.38(1.00$ to 1.91$)$ & $0.048^{*}$ \\
\hline Diabetes with complications & 2.08 (1.34 to 3.25$)$ & 0.001 & $1.86(0.97$ to 3.57$)$ & 0.063 \\
\hline Epilepsy & 3.15 (1.97 to 5.02$)$ & $<0.001$ & $1.01(0.58$ to 1.77$)$ & 0.972 \\
\hline Benign prostatic hypertrophy & 1.64 (0.89 to 3.05$)$ & 0.116 & 1.61 (0.81 to 3.22$)$ & 0.176 \\
\hline Peripheral vascular disease & 2.44 (1.27 to 4.68$)$ & 0.008 & 1.57 (0.77 to 3.19$)$ & 0.215 \\
\hline Osteoporosis/Paget's & $1.89(1.32$ to 2.71$)$ & 0.001 & $1.30(0.88$ to 1.93$)$ & 0.186 \\
\hline Myocardial infarction & 2.46 (1.32 to 4.59$)$ & 0.005 & $1.46(0.73$ to 2.94$)$ & 0.284 \\
\hline Diabetes uncomplicated & 1.40 (0.92 to 2.13$)$ & 0.114 & $0.76(0.41$ to 1.39$)$ & 0.374 \\
\hline Antiplatelets agents & 1.38 (1.03 to 1.85$)$ & 0.032 & $0.85(0.61$ to 1.17$)$ & 0.317 \\
\hline Chronic pulmonary disease & $2.10(1.30$ to 3.41$)$ & 0.003 & $1.31(0.74$ to 2.33$)$ & 0.349 \\
\hline Reactive airway disease & $1.33(0.96$ to 1.85$)$ & 0.091 & $0.89(0.60$ to 1.30$)$ & 0.538 \\
\hline Hypothyroidism & 1.63 (1.02 to 2.61$)$ & 0.042 & $1.22(0.74$ to 2.00$)$ & 0.442 \\
\hline Angina & 1.86 (1.28 to 2.68$)$ & 0.001 & $1.18(0.77$ to 1.79$)$ & 0.446 \\
\hline RA/collage vascular disorders & $2.63(1.06$ to 6.54$)$ & 0.038 & $1.38(0.49$ to 3.84$)$ & 0.542 \\
\hline Inflammatory bowel syndrome & $2.55(0.92$ to 7.06$)$ & 0.071 & $1.37(0.45$ to 4.17$)$ & 0.583 \\
\hline Liver disease (severe) or failure & 2.21 (1.24 to 3.93$)$ & 0.007 & $1.10(0.59$ to 2.04$)$ & 0.764 \\
\hline Congestive heart failure & $1.85(1.30$ to 2.64$)$ & 0.001 & $1.07(0.72$ to 1.60$)$ & 0.728 \\
\hline Parkinson's disease & 2.23 (0.97 to 5.12$)$ & 0.059 & $1.14(0.43$ to 3.01$)$ & 0.796 \\
\hline Renal disease/failure & 1.91 (1.10 to 3.32$)$ & 0.022 & $1.06(0.59$ to 1.91$)$ & 0.849 \\
\hline Other neurological disorder & 2.29 (0.92 to 5.68$)$ & 0.074 & $1.14(0.38$ to 3.44$)$ & 0.811 \\
\hline \multicolumn{5}{|l|}{ Other analgesic use } \\
\hline Pre-THA: hypnotics and sedatives & $2.31(1.70$ to 3.12$)$ & $<0.001$ & $1.56(1.13$ to 2.16$)$ & $0.007^{*}$ \\
\hline Pre-THA: antineuropathic pain & 4.72 (3.31 to 6.72$)$ & $<0.001$ & 3.11 (2.05 to 4.72$)$ & $<0.001^{*}$ \\
\hline Pre-THA: muscle relaxants & $4.22(0.87$ to 18.06$)$ & 0.053 & $1.95(0.39$ to 9.74$)$ & 0.416 \\
\hline Pre-THA: corticosteroids & 1.78 (1.25 to 2.55$)$ & 0.002 & $1.17(0.79$ to 1.74$)$ & 0.430 \\
\hline Bilateral procedure (more than 365 days) & $0.60(0.36$ to 1.00$)$ & 0.049 & $0.70(0.41$ to 1.20$)$ & 0.194 \\
\hline
\end{tabular}

*Significant variables $(p<0.05)$ in final model.

RA, rheumatoid arthritis; THA, total hip arthroplasty.

\section{DISCUSSION}

In this large cohort of patients who had undergone THAs, we determined that $6.2 \%$ of patients were chronic opioid users before surgery, and $5.2 \%$ were chronic opioid users after surgery. After THA, $61.4 \%$ of the chronic users of opioid had been chronic users before surgery, and $38.6 \%$ of them were new chronic users postsurgery. After evaluating patient characteristics, 56 patient comorbidities and other analgesic medication, we identified several risk factors associated with chronic opioid use.

Both sex and age were associated with chronic opioid use. Being female was associated with a $40 \%$ higher risk of developing chronic opioid use after surgery. Identifying women at a higher risk of chronic use in a
THA population is consistent with studies that evaluated different aspects of the sex and pain relationship. Specifically, women are at a higher risk of acute pain after THA surgery, ${ }^{31}$ as well as persistent and chronic postoperative pain $;{ }^{32}$ therefore, women had higher general utilisation of opioids in the long term. ${ }^{6}{ }^{7} \mathrm{We}$ also found that chronic opioid users were younger. While this was not a risk factor for development of new chronic opioid use post-THA, it was a risk factor for persistent chronic use or not reducing use after surgery. There is some evidence that younger patients are at a higher risk of persistent opioid use in the general surgical population. ${ }^{33}$ It has also been suggested that younger patients utilise higher perioperative opioid amounts. ${ }^{34}$ This higher utilisation is reported 
even without consistent evidence that younger patients experience greater pain from the procedure; for example, Liu et $a l^{1}$ reported higher scores for moderate-to-severe pain in younger patients, but Petre et $a \stackrel{P}{ }^{4}$ did not.

There are several opioid-related comorbidities associated with higher risk of chronic opioid use in our cohort. Back pain was the condition most consistently associated with chronic opioid use. Patients with back pain, diagnosed prior to surgery, were four times more likely to develop chronic opioid use if they did not already have it, and two times more likely to continue their chronic use after surgery. In the general population, back pain is one of the strongest predictors for opioid abuse, ${ }^{35}$ and its association with the pain and utilisation of opioids in a THA population ${ }^{7}$ is expectedly strong. ${ }^{20}$ Another condition commonly associated with high opioid utilisation and abuse, which was also found in our study, was depression. ${ }^{36}$ Depression was risk factor for new chronic opioid use. This has been reported in at least two other THA cohorts, one which assessed depression using patient medication assessments and one via a patient-reported questionnaire. ${ }^{31} 37$

One of the strongest general medical comorbidities risk factor for new opioid chronic use was pre-THA migraine, a condition associated with chronic pain and one where opioids are recommended for pain treatment. ${ }^{38}$ Liver disease was also strongly associated with new chronic opioid use, confirming previously reported associations in non-THA cohorts. ${ }^{39}$ Dementia, a moderate risk factor for new chronic use, was reportedly associated with chronic opioid use in general cohorts of patients, but to our knowledge, this is the first time it is reported in a THA cohort. ${ }^{40}$ The dispensing of proton-pump inhibitors was used to identify patients suffering from gastric acid disorder, a condition present in $44 \%$ of our cohort. We found this condition to be weakly associated with new chronic use development, which to our knowledge has also not been previously reported. We did not assess the duration of proton-pump inhibitors use. While the majority of people who took these medications did not become chronic opioid users, long-term use of proton-pump inhibitors has been shown to increase the risk of bone fracture $^{41}$ and surgical site infections, ${ }^{42}$ events that if present or developing after surgery could lead to the development of chronic opioid use after surgery. Weight loss, a moderate risk factor for new chronic use, and hyperlipidaemia, a borderline risk factor for chronic opioid use, were identified, but to our knowledge such associations have not been previously evaluated and we cannot, therefore, make comparisons. Finally, some established risk factors for chronic opioid use, including psychiatric comorbidities, alcohol and substance abuse, were not observed in our study. It is likely that these comorbidities were either well managed in these patients or the higher risk of opioid abuse in them was recognised and properly managed by their providers.
Diabetes was a moderate risk factor for persistent opioid use in this study. This has also been reported in other major elective surgical procedures ${ }^{33}$ and corroborates a recent report of it being associated with persistent pain post-THA. ${ }^{5}$ Rajamäki et a $\bar{l}^{5}$ suggested that either the constant chronic inflammation state that patients with diabetes are in or diabetic-related complications, such as neuropathy, could be associated with the mechanism to explain opioid use in patients with THA.

Prior opioid and adjuvant analgesics usage were also associated with risk of persistent or new chronic opioid use. The greater the number of days someone was dispensed opioids prior to surgery was associated with a higher likelihood of continuing to be a chronic user, which is consistent with studies reporting that the greater exposure to opioids, the greater the risk of abuse. ${ }^{43}$ Use of other medications, such tricyclic antidepressants and anticonvulsants, recommended for neuropathic pain, was also associated with a higher risk of persistent and new chronic use; this again confirms findings from general major elective surgical populations. ${ }^{33}$

Our study could not determine whether opioid use was associated with pain in the index joint. While we believe that opioid use is an efficient proxy for pain assessment measurement in joint replacement patients, as it identifies someone who has been prescribed a medication that is only recommended for refractory pain management, ${ }^{1}$ we understand that measuring and evaluating pain is difficult and more complex than only using opioid prescriptions. ${ }^{44}$ We also could not identify the reasons for the other analgesic medication patients were taking during the study timeline. It is possible they were prescribed these medications for reasons other than the joint pain. Additionally, our observational study used prescriptions to measure opioid use in this cohort of patients; therefore, we do not know whether patients were compliant to medication instructions.

Our study limitations include the conservative definition of chronic opioid user as someone who was prescribed opioids for 90 consecutive days or 120 non-consecutive days, which could miss the identification of opioid abuse (ie, overdoses or poisoning earlier on) in this patient population. We tried to include as many comorbidities, including those like migraine that is considered to be a chronic pain condition, in our analysis, but it is still possible that other chronic pain conditions, such as fibromyalgia, can be present and not accounted for in our analysis, both as a possible risk factor and as a confounder of the other relationships studied. Other confounding variables that we were unable to assess, such as body mass index, psychological well-being, function status, prescribers' preferences, as well as information regarding the index surgery, such as intraoperative complications, anaesthesia, length of stay and discharge destination, could affect the relationship between the risk factors we identified for persistent or new chronic use of opioid. Also, it is possible that due to 
the relatively low proportion of patients with some of the risk factors assessed, we may have been underpowered to detect associations between these factors and the likelihood of chronic or persistent opioid use. Finally, our study was comprised of an older cohort of Australian patients, making our results possibly less generalisable to a younger joint-replacement population.

The strengths of our study include our large patient cohort, which allowed for robust estimates on various risk factors. In an attempt to provide the most comprehensive assessment of patient comorbidities, we used three comorbidity measures to identify conditions using both inpatient hospitalisations and medication history. Our use of pharmacy data to determine opioid use, which provided us with more detailed information on the medication used by the study cohort, was less subject to recall bias than other studies that relied on patient or surgeon-reported measurements. Finally, the DVA administrative data used in this study covers all services provided to the Australian veteran population, assuring that we had complete data on all the procedures, hospitalisations and medications provided to these patients. This guaranteed to our study a low risk of missing data and attrition in the cohort.

\section{CONCLUSION}

Of the 492 (5\% of the total cohort) chronic opioid users after THA, $61 \%$ were persistent chronic users and $39 \%$ became chronic users after surgery. Back pain, diabetes and preoperative use of hypnotics were strong risk factors for the persistent and new development of chronic opioid use. Additional risk factors for persistent use included younger age and longer use of opioids prior to surgery, while for new chronic use these included being a woman, depression, migraine, gastric acid disease and antineuropathic pain medications. These indicators of chronic opioid use can be used by clinicians for risk stratification prior to THA surgery, and will help to target patient groups for suitable pain management interventions presurgery and postsurgery.

\author{
Author affiliations \\ ${ }^{1}$ Medicine and Device Surveillance Centre of Research Excellence, Sansom \\ Institute, School of Pharmacy and Medical Sciences, University of South \\ Australia, Adelaide, South Australia, Australia \\ ${ }^{2}$ Medicine and Devices Surveillance Centre of Research Excellence, School of \\ Pharmacy and Medical Sciences, University of South Australia, South \\ Australian Health and Medical Research Institute, Adelaide, South Australia, \\ Australia \\ ${ }^{3}$ Australian Orthopaedic Association National Total Joint Replacement \\ Registry, University of Adelaide, Adelaide, South Australia, Australia
}

Acknowledgements The authors acknowledge the provision of data for this study by the Australian Government Department of Veterans' Affairs (DVA). The DVA reviewed the manuscript to be submitted for publication.

Contributors MCSI, SEG, NLP and EER conceived the study idea and discussed it. MCSI, CH and NLP developed the protocol that was reviewed and edited by SEG and EER. MCSI performed data analyses. All authors reviewed and interpreted the data. MCSI wrote the first draft of the paper, which was revised by all authors. All authors provided permission to submit the final version of the paper.

Funding This work was supported by an Australian Government National Health and Medical Research Council (NHMRC) Centre of Research Excellence in Post-Marketing Surveillance of Medicines and Medical Devices grant (GNT1040938). NLP is supported by an NHMRC Early Career Fellowship (GNT1035889).

\section{Competing interests None declared.}

Ethics approval Ethics approval was obtained from the University of South Australia (P099-10), and the Australian Department of Veterans' Affairs (DVA) Human Research Ethics Committees (E010/010).

Provenance and peer review Not commissioned; externally peer reviewed.

Data sharing statement No additional data are available.

Open Access This is an Open Access article distributed in accordance with the Creative Commons Attribution Non Commercial (CC BY-NC 4.0) license, which permits others to distribute, remix, adapt, build upon this work noncommercially, and license their derivative works on different terms, provided the original work is properly cited and the use is non-commercial. See: http:// creativecommons.org/licenses/by-nc/4.0/

\section{REFERENCES}

1. Zhang W, Moskowitz RW, Nuki G, et al. OARSI recommendations for the management of hip and knee osteoarthritis, Part II: OARSI evidence-based, expert consensus guidelines. Osteoarthritis Cartilage 2008;16:137-62.

2. Healthcare Cost and Utilization Project (HCUP). Nationwide inpatient sample (NIS). Statistical Brief 186. Secondary Healthcare Cost and Utilization Project (HCUP). Nationwide inpatient sample (NIS). Statistical Brief 186. 2014. http://www.hcup-us.ahrq.gov/reports/ statbriefs/sb186-Operating-Room-Procedures-United-States-2012. pdf

3. Australian Institute of Health and Welfare (AIHW). Admitted patient care 2013-14: Australian hospital statistics. Secondary Australian Institute of Health and Welfare (AlHW). Admitted patient care 201314: Australian hospital statistics. 2014. http://www.aihw.gov.au/ publication-detail/?id=60129550483

4. Beswick AD, Wylde V, Gooberman-Hill R, et al. What proportion of patients report long-term pain after total hip or knee replacement for osteoarthritis? A systematic review of prospective studies in unselected patients. BMJ Open 2012;2:e000435.

5. Rajamäki TJ, Jämsen E, Puolakka PA, et al. Diabetes is associated with persistent pain after hip and knee replacement. Acta Orthop 2015;86:586-93.

6. Singh JA, Lewallen D. Predictors of pain and use of pain medications following primary total hip arthroplasty (THA): 5,707 THAs at 2-years and 3,289 THAs at 5-years. BMC Musculoskelet Disord 2010;11:90.

7. Valdes AM, Warner SC, Harvey HL, et al. Use of prescription analgesic medication and pain catastrophizing after total joint replacement surgery. Semin Arthritis Rheum 2015;45:150-5.

8. Hastie BA, Gilson AM, Maurer MA, et al. An examination of global and regional opioid consumption trends 1980-2011. J Pain Palliat Care Pharmacother 2014;28:259-75.

9. Morden NE, Munson JC, Colla CH, et al. Prescription opioid use among disabled Medicare beneficiaries: intensity, trends, and regional variation. Med Care 2014;52:852-9.

10. Frenk SM, Porter KS, Paulozzi LJ. Prescription opioid analgesic use among adults: United States, 1999-2012. NCHS Data Brief 2015;189:1-8.

11. Roxburgh A, Bruno R, Larance B, et al. Prescription of opioid analgesics and related harms in Australia. Med $J$ Aust 2011;195:280-4.

12. Larochelle MR, Zhang F, Ross-Degnan D, et al. Trends in opioid prescribing and co-prescribing of sedative hypnotics for acute and chronic musculoskeletal pain: 2001-2010. Pharmacoepidemiol Drug Saf 2015;24:885-92.

13. Levy B, Paulozzi L, Mack KA, et al. Trends in opioid analgesic-prescribing rates by specialty, U.S., 2007-2012. Am J Prev Med 2015;49:409-13.

14. Kehlet H, Dahl JB. Anaesthesia, surgery, and challenges in postoperative recovery. Lancet 2003;362:1921-8.

15. DuPen A, Shen D, Ersek M. Mechanisms of opioid-induced tolerance and hyperalgesia. Pain Manag Nurs 2007;8:113-21. 
16. Benyamin R, Trescot AM, Datta S, et al. Opioid complications and side effects. Pain Physician 2008;11(Suppl):S105-20.

17. Caughey GE, Vitry Al, Gilbert AL, et al. Prevalence of comorbidity of chronic diseases in Australia. BMC Public Health 2008;8:221.

18. Cram P, Lu X, Kaboli PJ, et al. Clinical characteristics and outcomes of Medicare patients undergoing total hip arthroplasty, 1991-2008. JAMA 2011;305:1560-7.

19. Vogeli C, Shields AE, Lee TA, et al. Multiple chronic conditions: prevalence, health consequences, and implications for quality, care management, and costs. J Gen Intern Med 2007;22(Suppl 3):391-5.

20. Lanting BA, MacDonald SJ. The painful total hip replacement: diagnosis and deliverance. Bone Joint $J$ 2013;95-B(Suppl A):70-3.

21. WHO. Collaborating centre for drug statistics methodology, guidelines for ATC classification and DDD assignment. 2014. Oslo, Norway, 2013. http://www.whocc.no/filearchive/publications/1 2013guidelines.pdf

22. Health AGDo. Australian Goverment Department of Health Pharmaceutical Benefits Services. Secondary Australian Goverment Department of Health. Pharmaceutical Benefits Services. 2014. http://www.pbs.gov.au/browse/medicine-listing

23. International Statistical Classification of Diseases and Related Health Problems, Tenth Revision, Australian Modification (ICD-10-AM). Secondary International Statistical Classification of Diseases and Related Health Problems, Tenth Revision, Australian Modification (ICD-10-AM) July 2013. 2013. https://www.accd.net.au/lcd10.aspx

24. Von Korff M, Saunders K, Thomas Ray G, et al. De facto long-term opioid therapy for noncancer pain. Clin J Pain 2008;24:521-7.

25. Australian and New Zealand College of Anaesthetist FoPM. Opioid Conversion to oral Morphine Equivalent Daily Dose (oMEDD). Secondary Opioid Conversion to oral Morphine Equivalent Daily Dose (oMEDD). 2014. http://www.fpm.anzca.edu.au/resources/ professional-documents/OPIOID20DOSE20EQUIVALENCE.pdf

26. Quan $\mathrm{H}$, Sundararajan V, Halfon $\mathrm{P}$, et al. Coding algorithms for defining comorbidities in ICD-9-CM and ICD-10 administrative data. Med Care 2005;43:1130-9.

27. Fishman PA, Goodman MJ, Hornbrook MC, et al. Risk adjustment using automated ambulatory pharmacy data: the RxRisk model. Med Care 2003;41:84-99.

28. Votrubec M, Thong I. Neuropathic pain-a management update. Aust Fam Physician 2013:42:92-7.

29. Pandeya N, Green AC, Whiteman DC, et al. Prevalence and determinants of frequent gastroesophageal reflux symptoms in the Australian community. Dis Esophagus 2012;25:573-83.

30. Ruszniewski P, Soufflet $C$, Barthélémy P. Nonsteroidal anti-inflammatory drug use as a risk factor for gastro-oesophageal reflux disease: an observational study. Aliment Pharmacol Ther 2008;28:1134-9.

31. Liu SS, Buvanendran A, Rathmell JP, et al. Predictors for moderate to severe acute postoperative pain after total hip and knee replacement. Int Orthop 2012;36:2261-7.

32. Nikolajsen $\mathrm{L}$, Brandsborg B, Lucht $U$, et al. Chronic pain following total hip arthroplasty: a nationwide questionnaire study. Acta Anaesthesiol Scand 2006;50:495-500.

33. Clarke H, Soneji N, Ko DT, et al. Rates and risk factors for prolonged opioid use after major surgery: population based cohort study. BMJ 2014;348:g1251.

34. Petre BM, Roxbury CR, McCallum JR, et al. Pain reporting, opiate dosing, and the adverse effects of opiates after hip or knee replacement in patients 60 years old or older. Geriatr Orthop Surg Rehabil 2012;3:3-7.

35. Deyo RA, Von Korff M, Duhrkoop D. Opioids for low back pain. BMJ 2015;350:g6380.

36. Sehgal N, Manchikanti L, Smith HS. Prescription opioid abuse in chronic pain: a review of opioid abuse predictors and strategies to curb opioid abuse. Pain Physician 2012;15Suppl):ES67-92.

37. Wylde $\mathrm{V}$, Jeffery $\mathrm{A}$, Dieppe $\mathrm{P}$, et al. The assessment of persistent pain after joint replacement. Osteoarthritis Cartilage 2012;20:102-5.

38. Silberstein SD. Practice parameter: evidence-based guidelines for migraine headache (an evidence-based review): report of the Quality Standards Subcommittee of the American Academy of Neurology. Neurology 2000;55:754-62.

39. Rogal SS, Winger D, Bielefeldt $\mathrm{K}$, et al. Pain and opioid use in chronic liver disease. Dig Dis Sci 2013:58:2976-85.

40. Jensen-Dahm C, Gasse C, Astrup A, et al. Frequent use of opioids in patients with dementia and nursing home residents: a study of the entire elderly population of Denmark. Alzheimers Dement 2015;11:691-9.

41. Yu EW, Bauer SR, Bain PA, et al. Proton pump inhibitors and risk of fractures: a meta-analysis of 11 international studies. Am J Med 2011;124:519-26.

42. Sadoghi $\mathrm{P}$, Liebensteiner $\mathrm{M}$, Agreiter $\mathrm{M}$, et al. Revision surgery after total joint arthroplasty: a complication-based analysis using worldwide arthroplasty registers. J Arthroplasty 2013;28:1329-32.

43. Edlund MJ, Steffick D, Hudson T, et al. Risk factors for clinically recognized opioid abuse and dependence among veterans using opioids for chronic non-cancer pain. Pain 2007;129:355-62.

44. Breivik $\mathrm{H}$, Borchgrevink PC, Allen SM, et al. Assessment of pain. Br J Anaesth 2008;101:17-24. 